\title{
Adaptações morfofisiológicas da soja em solo inundado(1)
}

\author{
João Leonardo Fernandes Pires ${ }^{(2)}$, Eliséo Soprano ${ }^{(3)}$ e Bibiana Cassol(4)
}

\begin{abstract}
Resumo - Há restrições ao crescimento de plantas em condições de inundação do solo, o que limita a sua exploração agrícola a poucas espécies. A soja pode ser uma alternativa, pela alta capacidade adaptativa a estas condições. O objetivo deste trabalho foi identificar as formas de adaptação da soja à inundação do solo, e estabelecer a melhor estratégia para fornecimento de $\mathrm{N}$ em solos inundados. Foi conduzido um experimento em casa de vegetação, na Faculdade de Agronomia da Universidade Federal do Rio Grande do Sul (UFRGS), de setembro a novembro de 1998. Foram testadas duas cultivares de soja (FT-Abyara e BR 4) cultivadas sob dois regimes hídricos (inundação e capacidade de campo) e duas estratégias de fornecimento de N (inoculação e N mineral). Manteve-se a soja sob inundação do estádio V2 até V5 (21 dias). A soja apresentou mecanismos que permitem sua adaptação a condições de hipoxia geradas pela inundação do solo. Houve redução nos teores de $\mathrm{N}, \mathrm{K}, \mathrm{Mg}$ e $\mathrm{Mn}$, e aumento nos teores de Fe nas folhas, quando da inundação. Existiram diferenças entre cultivares em solo inundado, destacando-se a cultivar FT-Abyara, pela maior adaptação. O diâmetro do caule sob a lâmina de água foi a característica mais importante na diferenciação de cultivares com vistas a tolerância à inundação. A melhor estratégia para fornecimento de $\mathrm{N}$ em condições de solo inundado foi a aplicação de $\mathrm{N}$ mineral em cobertura. Porém, mesmo em solo inundado ocorreu nodulação em soja.
\end{abstract}

Termos para indexação: Glycine max, caule, raízes adventícias, anoxia, regime hídrico do solo.

\section{Morphophysiologic changes of soybean in flooded soils}

\begin{abstract}
There are restrictions to the growth of plants in flooded soils, and this limits their agricultural exploration to few species. Soybean is becoming an alternative, due to its high adaptation capacity to these conditions. The objective of this work was to identify the forms of adaptation of soybean in flooded soils, and to establish the best strategy for supplying $\mathrm{N}$ in flooded conditions. An experiment was carried out in greenhouse in the Faculdade de Agronomia of Universidade Federal do Rio Grande do Sul (UFRGS), in Brazil, from September to November 1998. Two cultivars of soybean (FT-Abyara and BR 4) grown under two humidity conditions (flooded soil and field capacity) and two strategies for supplying nitrogen (inoculation and mineral $\mathrm{N}$ ) were tested. The soybean stayed under flood from stadium V2 to V5 (21 days). Soybean presented mechanisms (stem base hypertrophy and adventitious roots with aerenchyma), that allowed its adaptation to hypoxia conditions under flooded soil. There was reduction in the levels of $\mathrm{N}, \mathrm{K}, \mathrm{Mg}$ and $\mathrm{Mn}$ and increase in the level of $\mathrm{Fe}$ in the leaves when flooded. Differences existed between cultivars under flooded soil; cultivar FT-Abyara was the best adapted. Stem diameter under flooded conditions was the most important characteristic in the differentiation of cultivars for tolerance to flooding. The best strategy for supplying $\mathrm{N}$ in conditions of flooded soil was the application of mineral $\mathrm{N}$ in covering. Even under flood, nodulation in soybean happened.
\end{abstract}

Index terms: Glycine max, stems, adventitious roots, anoxia, soil water regimes.

\footnotetext{
(1) Aceito para publicação em 29 de janeiro de 2001.

${ }^{(2)}$ Universidade Federal do Rio Grande do Sul (UFRGS), Fac. de Agronomia, Caixa Postal 776, CEP 90001-970 Porto Alegre, RS. Bolsista do CNPq. E-mail: piresj1@vortex.ufrgs.br

${ }^{(3)}$ UFRGS, Fac. de Agronomia. Bolsista da Embrapa. E-mail: esoprano@epagri.rct-sc.br

(4)UFRGS, Dep. de Botânica. E-mail: bcassol@vortex.ufrgs.br
}

\section{Introdução}

O Estado do Rio Grande do Sul possui dois milhões de hectares utilizados com cultivo de arroz irrigado, sendo $25 \%$ deste total utilizado anualmente, e o restante, não explorado com culturas produtoras de grãos, com o objetivo de reduzir a incidência de 
plantas daninhas (Costa, 1996). Vários trabalhos têm sido conduzidos com a finalidade de buscar alternativas para cultivos nas várzeas arrozeiras, proporcionando maior retorno econômico dessas áreas (Barni et al., 1985; Gastal et al., 1998). O grande problema é a difícil adaptação de culturas que possibilitem retorno econômico em solos alagados, uma vez que a maior parte das culturas produtoras de grãos são mesófitas. Buscam-se, como alternativas, espécies que permitam a utilização da mesma estrutura empregada no arroz, apresentem mecanismos de tolerância às condições impostas pela inundação do solo, e possuam elevado potencial de rendimento. Para isso, a cultura da soja aparece como boa alternativa.

O encharcamento modifica a atmosfera do solo, pois promove deficiência de $\mathrm{O}_{2}$, acúmulo de $\mathrm{CO}_{2}$, metano, etileno, gás sulfídrico $\left(\mathrm{H}_{2} \mathrm{~S}\right), \mathrm{H}$ e redução da respiração aeróbica. O crescimento das raízes paralisa-se em poucos minutos, com o limite de tolerância das raízes de soja em relação ao $\mathrm{CO}_{2}$, que é 20\% na atmosfera do solo (Costa, 1996).

O estresse experimentado pelas raízes sob inundação intensifica-se com o tempo, com a passagem de hipoxia para anoxia e pela ação de toxinas produzidas por bactérias anaeróbicas do solo. Anoxia e toxinas podem matar as raízes, mas algumas das respostas iniciais à hipoxia e à ação do etileno permitem que as raízes evitem a anoxia e toxificação, se a inundação persistir (Jackson, 1985).

A diminuição no teor de $\mathrm{O}_{2}$ provoca desordens metabólicas na planta (uma das principais é a respiração anaeróbica), diminuindo a eficiência na utilização de $\mathrm{C}$ e aumentando a produção de etanol e lactato (Marschner, 1995). A deficiência de $\mathrm{O}_{2}$ prejudica a síntese de fitorreguladores, tais como giberelinas e citocininas (Smit et al., 1990).

Existem mecanismos adaptativos nas plantas para tolerar a deficiência de $\mathrm{O}_{2}$. $\mathrm{O}$ arroz tem a capacidade de transferir $\mathrm{O}_{2}$ da atmosfera para as raízes, através das folhas e do caule. Nas raízes, este é excretado na rizosfera, formando uma região de oxidação, e assim, reduz o efeito ou a disponibilidade de substâncias tóxicas $\left(\mathrm{Fe}^{2+}\right.$ e $\left.\mathrm{Mn}^{2+}\right)$. Da mesma forma, a soja apresenta mecanismos adaptativos a condições de solo inundado, que lhe permitem sobreviver em condições de restrição de $\mathrm{O}_{2}$ (Bacanamwo \& Purcell, 1999b). De acordo com Bartlett \& James (1993), a habilidade das plantas em tolerar condições com restrição de $\mathrm{O}_{2}$ está ligada com a habilidade das raízes em oxidar a rizosfera por meio da transferência de $\mathrm{O}_{2}$ da parte aérea para as raízes.

VanToai \& Beuerlein (1994), avaliando 84 cultivares de soja em condições de inundação do solo, verificaram que, em média, as cultivares produziram $25 \%$ a menos que em condições de solo não inundado. Os mesmos autores demonstraram, também, que existem diferenças na tolerância à inundação entre cultivares de soja utilizadas nos Estados Unidos.

A inundação do solo prejudica a nodulação de leguminosas e inibe a fixação de $\mathrm{N}_{2}$ em nódulos previamente formados (Jackson, 1985). Na soja, esse efeito não deve ser diferente, pois traz prejuízos na associação com Bradyrhizobium japonicum, e torna necessária a aplicação de $\mathrm{N}$ na forma mineral para plantas cultivadas sob inundação.

O objetivo deste trabalho foi identificar as formas adaptativas da soja à inundação do solo, e estabelecer a melhor estratégia para fornecimento de $\mathrm{N}$ em condições de inundação.

\section{Material e Métodos}

O experimento foi conduzido em casa de vegetação do Departamento de Solos da Faculdade de Agronomia da Universidade Federal do Rio Grande do Sul (UFRGS), no período de setembro a novembro de 1998. Utilizaram-se vasos de $1 \mathrm{~L}$, com solo hidromórfico (Planossolo da unidade de mapeamento Vacacaí), característico de várzeas arrozeiras coletado na Estação Experimental do Instituto Riograndense do Arroz (Irga), no Município de Cachoeirinha, RS. O solo coletado da camada de 0 a $20 \mathrm{~cm}$ foi secado, destorroado, e passado em peneira de $5 \mathrm{~mm}$ de malha. As características do solo foram as seguintes: $\mathrm{pH}$ $\left(\mathrm{H}_{2} \mathrm{O}\right)$ 5,5; índice SMP 7,1; P, 8,2 $\mathrm{mg} \mathrm{kg}^{-1} ; \mathrm{K}, 76 \mathrm{mg} \mathrm{kg}^{-1}$; $\mathrm{MO}, 14 \mathrm{~g} \mathrm{~kg}^{-1}$; Al, 0,4 $\mathrm{cmol}_{\mathrm{c}} \mathrm{L}^{-1}$; Ca, 1,9 $\mathrm{cmol}_{\mathrm{c}} \mathrm{L}^{-1} ; \mathrm{Mg}$, $0,7 \mathrm{cmol}_{\mathrm{c}} \mathrm{L}^{-1}$; argila, $130 \mathrm{~g} \mathrm{~kg}^{-1}$; capacidade de campo, $15 \%$ e densidade aparente, $1,31 \mathrm{~g} \mathrm{~cm}^{-3}$. Como tratamentos, testaram-se duas cultivares: FT-Abyara e BR 4; dois regimes de umidade do solo: capacidade de campo e inundação; e duas formas de suprimento de $\mathrm{N}$ para as plantas: com a semente submetida a inoculação, e com aplicação de $\mathrm{N}$ mineral em cobertura, na forma de um fatorial $2^{3}$. O delineamento empregado foi completamente casualizado, com quatro repetições. As cultivares utilizadas representam extremos de adaptação à condição de solo 
inundado; a cultivar BR 4 não foi indicada para essa condição (Reunião..., 1998), e a FT-Abyara que tem demonstrado ser tolerante a solos de várzea com excesso de umidade. A adubação do solo foi feita com P e K, utilizando-se, como fonte, fosfato dibásico de potássio. A semeadura foi realizada com sementes de soja pré-germinadas, submetidas à inoculação de estirpes específicas de Bradyrhizobium japonicum (nos tratamentos com inoculação), e os vasos foram mantidos na capacidade de campo até o estádio V2 (segundo nó, de acordo com Costa \& Marchezan, 1982). Nesse estádio, realizou-se a inundação dos vasos que receberam esse tratamento, mantendo-se a lâmina de água a $3 \mathrm{~cm}$ acima do solo. Aos dois dias após a inundação, aplicou-se a dose de $100 \mathrm{mg} \mathrm{kg}^{-1} \mathrm{de} \mathrm{N}$, na forma de uréia, nos vasos que receberam esse tratamento. Conduziu-se o experimento até o estádio V5 (cinco nós, aos 21 dias após a inundação). Após a coleta das plantas, determinou-se a massa de matéria seca, área foliar, volume de raízes, teores de $\mathrm{N}, \mathrm{K}, \mathrm{Ca}, \mathrm{Mg}, \mathrm{Fe}$ e Mn nas folhas. A extração da solução do solo foi feita pelo método da centrífuga, descrito por Elkhatib et al. (1987) e adaptado por Fernandes (1989), e determinaram-se a condutividade elétrica (CE), o pH, os teores de $\mathrm{N}\left(\mathrm{NH}_{4}{ }^{+} \mathrm{e}\right.$ $\mathrm{NO}_{3}{ }^{-}$), $\mathrm{Fe}$ e Mn. Nas determinações de solo e planta, utilizaram-se os métodos descritos por Tedesco et al. (1995). Foi coletado material vegetal para a realização de cortes anatômicos. Para realização dos cortes transversais das raízes adventícias, o material foi fixado em glutaraldeído 2,5\% em tampão fosfato ( $\mathrm{pH} 7,2)$, desidratado em série etílica e incluído em hidroxietilmetacrilato. As secções foram feitas em micrótomo de guias (Laica 1400) com espessuras de $5 \mu \mathrm{m}$. O material seccionado foi corado com azul de toluidina ( $\mathrm{pH} 4,5)$ e montado em bálsamo do Canadá sintético. As fotomicrografias foram obtidas em microscópio óptico (Leitz/Dialux - 20EB) com equipamento fotográfico acoplado (Lica/MD-2).

A análise estatística foi realizada pela análise de variância (teste $\mathrm{F}$ a 5\%), e as médias dos tratamentos foram comparadas pelo teste de Tukey a $5 \%$.

\section{Resultados e Discussão}

Os principais efeitos da inundação do solo foram verificados nas raízes das plantas, as quais apresentaram mudanças anatômico-morfológicas para se adaptarem ao ambiente de hipoxia. Houve morte da raiz principal, crescimento de raízes laterais, surgimento de raízes adventícias, e redução dos teores de nutrientes nas folhas. Esse tratamento apresentou alterações na dinâmica de nutrientes no solo.
Ocorreu elevação de $\mathrm{pH}, \mathrm{CE}$, teores de Fe e Mn, e redução dos teores de $\mathrm{N}$ na solução do solo (Tabela 1). A elevação do $\mathrm{pH}(5,0$ para 6,2$)$ é um fenômeno comum em solos ácidos, quando inundados, e é atribuído ao consumo de $\mathrm{H}^{+}$quando da redução do $\mathrm{Fe}^{3+}$, segundo a seguinte reação: $\mathrm{Fe}(\mathrm{OH})_{3}+3 \mathrm{H}^{+}+$ $\mathrm{e}^{-}=\mathrm{Fe}^{2+}+3 \mathrm{H}_{2} \mathrm{O}$. A elevação da $\mathrm{CE}$ é atribuída ao aumento da concentração de sais na solução do solo, principalmente em virtude da mobilização do $\mathrm{Fe} e$ $\mathrm{Mn}$, ao acúmulo de $\mathrm{NH}_{4}^{+}, \mathrm{HCO}_{3}{ }^{-}$e $\mathrm{RCOO}^{-}$, e ao deslocamento de cátions nos colóides do solo pelo $\mathrm{Fe}^{2+}, \mathrm{Mn}^{2+} \mathrm{e} \mathrm{NH}_{4}^{+}$(Dedatta, 1981). A solubilização e redução de óxidos e hidróxidos pelos microrganismos que utilizam $\mathrm{Fe}^{3+}$ e $\mathrm{Mn}^{4+}$ como receptores de elétrons aumentam as formas $\mathrm{Fe}^{2+} \mathrm{e} \mathrm{Mn}^{2+}$ solúveis, absorvidas pelas plantas. Os teores de Fe passaram de 0,5 para $47 \mathrm{mg} \mathrm{L}^{-1}$; e os de $\mathrm{Mn}$, de 1,1 para 3,0 $\mathrm{mg} \mathrm{L}^{-1}$ com 21 dias de inundação. Quanto aos teores de N mineral total, verificou-se que houve uma diminuição de 81 para $13 \mathrm{mg} \mathrm{L}^{-1}$ com a inundação, possivelmente por imobilização ou perdas por desnitrificação. A presença de $\mathrm{NO}_{3}{ }^{-}$no solo inundado sugere que o processo de desnitrificação ainda estava ocorrendo. Em solo inundado, a forma de $\mathrm{N}$ predominante foi $\mathrm{NH}_{4}^{+}$.

Verificou-se, na condição de solo inundado, redução nas quantidades de N, K, Mg e Mn, e aumento do Fe na parte aérea da soja (Tabela 2). Os teores de Ca não foram afetados pela inundação do solo. Com a diminuição do teor de $\mathrm{O}_{2}$, ocorrem restrições no metabolismo da planta, prejudicando a absorção e o transporte de íons (Drew \& Stolzy, 1991). Como conseqüência, ocorre redução dos teores desses nutrientes na parte aérea. Os altos teores de Fe são devidos aos altos níveis de $\mathrm{Fe}^{2+}$ no solo inundado, em conseqüência da redução dos compostos de forma $\mathrm{Fe}^{3+}$ para a forma $\mathrm{Fe}^{2+}$. Esta última, sendo mais solúvel, é absorvida em excesso pelas plantas, e pode alcançar níveis tóxicos. Os baixos teores de Mn nas folhas se devem ao fato de o solo utilizado ser de origem sedimentar, portanto pobre em Mn, bem como pelo efeito competitivo com os altos teores de $\mathrm{Fe}$ na solução.

Resultados semelhantes foram encontrados por Barni (1999), em que os teores de K, Mg e Mn no tecido foliar de soja diminuíram com a duração da inundação do solo. Também verificou diminuição nos 
teores de $\mathrm{P} \mathrm{e}$ Ca nessas condições. Em relação ao Fe, obteve níveis bastante altos, atingindo $3.032 \mathrm{ppm}$ com inundação imposta até o início da floração.

Em relação às alterações morfofisiológicas nas plantas, verificou-se que, em solo inundado, houve várias formas de adaptação à condição de estresse imposta pela redução do $\mathrm{O}_{2}$. Inicialmente, ocorreu epinastia foliar e formação de rachaduras no caule na região submersa, já algumas horas após a inundação. Posteriormente, houve alargamento (hipertrofia) e formação de uma região esponjosa na base do caule, e também o surgimento de raízes adventícias. Observou-se a morte da raiz principal e o desenvolvimento de raízes laterais, diferentemente do que ocorreu nas condições de capacidade de campo, onde o padrão das raízes não foi alterado. A maior parte dessas modificações é desencadeada pela elevação nos teores de etileno interno, quando da inundação (Jackson, 1985). Constatou-se deposição de óxidos de ferro, principalmente na região onde ocorreu morte da raiz principal. Na parte aérea, verificaram-se sintomas de toxidez, possivelmente de ferro, pois os teores desse elemento no tecido foram bastante elevados (Tabela 2).
Os cortes anatômicos realizados em raízes adventícias das plantas cultivadas sob inundação evidenciaram elevada ruptura das células do córtex (indicando a formação de um aerênquima lisígeno), criando espaços vazios, servindo como condutos para a transferência de $\mathrm{O}_{2}$ para as raízes. A epiderme e o cilindro central das plantas não sofreram modificações nas condições de inundação, a não ser pelo rompimento da epiderme, que pode ser constatada também, visualmente, nas raízes e caule inundados ( $\mathrm{Fi}$ gura 1).

Essas evidências indicam a formação de um aerênquima semelhante ao que ocorre em milho (Drew et al., 2000) e arroz, embora em soja tenha ocorrido ruptura das células da epiderme, o que não ocorre em milho e arroz. Uma hipótese para a formação do aerênquima lisígeno é a ocorrência deste em resposta a um aumento no nível de etileno, que ativa a enzima celulase, ocorrendo a lise da célula. Nesse mecanismo está envolvida também uma rota de transdução de um sinal envolvendo fosfoinositases e $\mathrm{Ca}^{2+}$, que atua como mensageiro, sinalizando endonucleases que degradam o DNA do núcleo celular de forma semelhante ao processo chamado

Tabela 1. Teores de nutrientes, valores de $\mathrm{pH}$ e condutividade elétrica (CE), na solução do solo, em dois regimes hídricos ${ }^{(1)}$.

\begin{tabular}{lcccccc}
\hline Regime hídrico & ${\mathrm{N}-\mathrm{NO}_{3}^{-}}^{-}$ & $\mathrm{N}^{-\mathrm{NH}_{4}{ }^{+}}$ & $\mathrm{Fe}$ & $\mathrm{Mn}$ & $\mathrm{pH}\left(\mathrm{H}_{2} \mathrm{O}\right)$ & $\begin{array}{c}\mathrm{CE} \\
\left(\mathrm{mS} \mathrm{m}^{-1}\right)\end{array}$ \\
\hline Inundado & $3 \mathrm{~b}$ & $10 \mathrm{~b}$ & $47,0 \mathrm{a}$ & $3,0 \mathrm{a}$ & $6,2 \mathrm{a}$ & $47 \mathrm{a}$ \\
Capacidade de campo & $40 \mathrm{a}$ & $41 \mathrm{a}$ & $0,5 \mathrm{~b}$ & $1,1 \mathrm{~b}$ & $5,0 \mathrm{~b}$ & $30 \mathrm{~b}$ \\
\hline $\mathrm{CV}(\%)$ & 43 & 20,2 & 25 & 27,1 & 5,8 & 12,6 \\
\hline
\end{tabular}

${ }^{(1)}$ Médias seguidas da mesma letra, na coluna, não diferem entre si a $5 \%$ de probabilidade, pelo teste de Tukey.

Tabela 2. Teores de nutrientes em folhas de duas cultivares de soja sob dois regimes hídricos ${ }^{(1)}$

\begin{tabular}{|c|c|c|c|c|c|c|}
\hline \multirow{3}{*}{$\begin{array}{l}\text { Regime hídrico } \\
\text { Solo inundado }\end{array}$} & \multirow{3}{*}{$\begin{array}{c}\mathrm{N} \\
-\cdot-\cdot- \\
43,0 b\end{array}$} & \multirow{2}{*}{$\mathrm{K}$} & \multirow[t]{2}{*}{$\mathrm{Ca}$} & \multirow{2}{*}{ Mg } & \multirow{2}{*}{\multicolumn{2}{|c|}{ Fe $\left(\mathrm{mg} \mathrm{kg}^{-1}\right)$ Mn }} \\
\hline & & & & & & \\
\hline & & $15,0 \mathrm{~b}$ & $8,3^{\text {ns }}$ & $3,4 b$ & $825 a$ & $242 b$ \\
\hline Capacidade de campo & $48,0 \mathrm{a}$ & $18,2 \mathrm{a}$ & 7,8 & $4,3 \mathrm{a}$ & $295 b$ & $321 \mathrm{a}$ \\
\hline Suficiente ${ }^{(2)}$ & $40-55$ & $17-25$ & $3,6-20$ & $2,6-10$ & $51-350$ & $21-100$ \\
\hline CV $(\%)$ & 4,9 & 6,1 & 5,1 & 5,1 & 14,9 & 3,5 \\
\hline
\end{tabular}

${ }^{(1)}$ Médias seguidas da mesma letra, na coluna, não diferem entre si a 5\% de probabilidade, pelo teste de Tukey. ${ }^{(2)}$ Segundo Sfredo \& Carrão-Panizzi (1990). ns Não-significativo. 
Morte Programada de Células (He et al., 1996; Drew et al., 2000). No entanto, não se conhece como esta lise de células ocorre de forma localizada e sistemática.

O principal fator a ser considerado na avaliação do nível de tolerância da soja à inundação do solo é representado pela produção de matéria seca. No presente trabalho, a cultivar FT-Abyara produziu mais matéria seca na parte aérea, raízes e área foliar do que a cultivar BR 4 em condições de solo inundado (Tabela 3). Não se verificaram, no entanto, diferenças na matéria seca da parte aérea, na área foliar e na estatura, pela inundação do solo em relação à capacidade de campo. A matéria seca de raízes foi maior em condições de inundação do solo, provavelmente pela formação de raízes adventícias em profusão nessa situação (Tabela 4).

A hipertrofia do caule, representada pelo diâmetro do caule sob a lâmina de água, foi bastante superior à observada nas plantas sem inundação, em ambas as cultivares (Figura 2). Em condições de inundação, a cultivar FT-Abyara foi superior à cultivar BR 4 para este parâmetro (Figura 3). Essa foi a característica mais evidente na diferenciação da tolerância à inundação entre as cultivares.
Trabalhos indicam que a hipertrofia do caule pode estar associada com o espaço intercelular, quebra de células para formar aerênquima e subseqüente formação de raízes adventícias (Jackson, 1985). Portanto, os resultados obtidos podem indicar formação de maior quantidade de tecido aerenquimatoso na cultivar FT-Abyara, o que pode, em parte, explicar o melhor crescimento desta em condições de inundação do solo.

Com relação à estratégia para fornecimento de $\mathrm{N}$, verificou-se que, sob inundação, a adição de $\mathrm{N}$ mineral possibilitou maior produção de matéria seca e área foliar em relação à inoculação (Tabela 5). Isto é evidenciado pelos teores de $\mathrm{N}$ presentes nas folhas. No entanto, a inundação do solo não afetou a produção de matéria seca, área foliar, teor de $\mathrm{N}$ e matéria seca de nódulos quando se realizou inoculação, o que demonstra que a nodulação não foi afetada pela inundação, e observou-se, mesmo após 21 dias sob lâmina de água, a presença de nódulos ativos e em quantidade equivalente aos observados em solos mantidos à capacidade de campo (5,3 e 4,1 nódulos/planta no solo inundado e na capacidade de campo, respectivamente). A adição de uréia em solo inundado aumentou a produção de matéria seca das plantas,

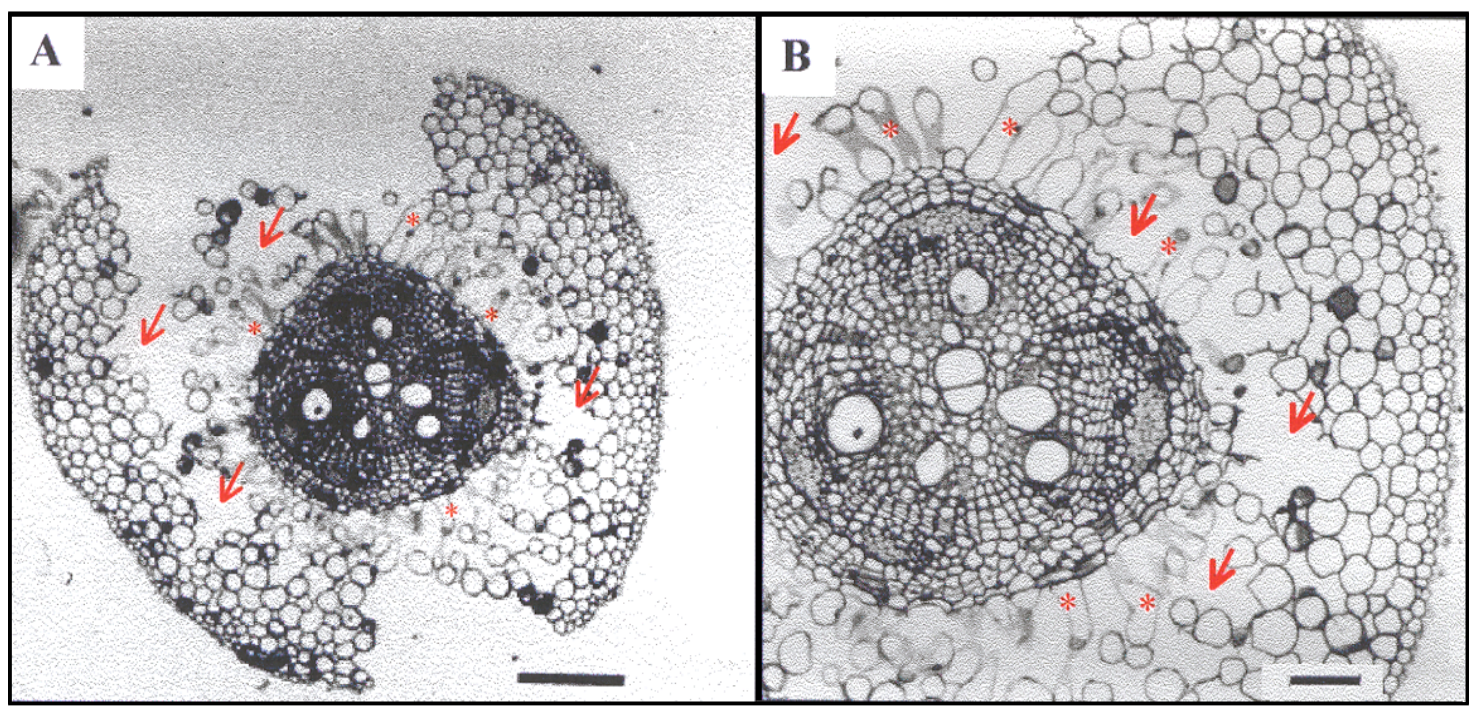

Figura 1. Fotomicrografia da secção transversal de raiz adventícia de soja (estádio V5), 21 dias após a inundação do solo: A) barra $=250 \mu \mathrm{m}, \mathrm{B})$ barra $=100 \mu \mathrm{m}$. As setas indicam os espaços intercelulares, e os asteriscos, o tecido do aerênquima. 
embora não tenha elevado a área foliar e os teores de $\mathrm{N}$ nas folhas, em comparação com essa produção ocorrida em solo na capacidade de campo (Tabela 5).

De-Polli et al. (1973) constataram que o solo com $25 \%$ de umidade acima da capacidade de campo, em condições constantes, não prejudicou a nodulação e a fixação de $\mathrm{N}_{2}$ na cultivar de soja Santa Maria. Esses autores afirmam a probabilidade de haver nodulação eficiente e fixação de $\mathrm{N}_{2}$ em solos com excesso de umidade, desde que ocorra inoculação suficiente.

Em experimento realizado por Bacanamwo \& Purcell (1999b), ficou evidente o efeito da fonte nitrogenada sobre a formação de aerêmquima. Tratamentos com nitrato reduziram o desenvolvimento do aerênquima em $55 \%$, em relação às plantas fixadoras de $\mathrm{N}_{2}$. Embora a inundação na presença de nitrato reduza o aerênquima, este aumenta as raízes adventícias e proporciona aumento de crescimento. Esse efeito pode ter acontecido no presente experimento; no entanto, teriam que ter sido quantificados o aerênquima e as raízes adventícias, o que não foi realizado. Sabe-se que a aplicação de adubação nitrogenada em soja em condições de inundação seria um fator negativo do ponto de vista econômico,

Tabela 3. Parâmetros de crescimento de cultivares de soja em solo inundado ${ }^{(1)}$.

\begin{tabular}{|c|c|c|c|}
\hline \multirow[t]{2}{*}{ Cultivar } & \multicolumn{2}{|c|}{ Matéria seca } & \multirow{2}{*}{$\begin{array}{l}\text { Área foliar } \\
\left(\mathrm{cm}^{2} \text { planta }^{-1}\right)\end{array}$} \\
\hline & $\begin{array}{l}\text { Parte aérea } \\
-\mathrm{g}_{\text {planta }}\end{array}$ & $\begin{array}{l}\text { Raízes } \\
\text { 1) ----- }\end{array}$ & \\
\hline FT Abyara & $1,94 \mathrm{a}$ & $0,7 \mathrm{a}$ & $218 \mathrm{a}$ \\
\hline BR 4 & $1,20 \mathrm{~b}$ & $0,3 b$ & $151 b$ \\
\hline CV (\%) & 16 & 20,3 & 12,7 \\
\hline
\end{tabular}

${ }^{(1)}$ Médias seguidas da mesma letra, na coluna, não diferem entre si a $5 \%$ de probabilidade, pelo teste de Tukey. como ocorre em lavouras tradicionalmente cultivadas com a leguminosa. Portanto, é importante salientar que a aclimatação da soja à inundação deve ensejar que sejam alocados os fotoassimilados preferencialmente para o desenvolvimento de raízes adventícias porosas, e que a formação de aerênquima, para a soja dependente da fixação de $\mathrm{N}_{2}$, seja considerada fundamental para tal aclimatação (Bacanamwo \& Purcell, 1999a).

Numa situação de deficiência de N, ocorre aumento no desenvolvimento do aerênquima pela maior sensibilidade das células corticais ao etileno, causando a quebra mais rápida das células na presença de baixas concentrações do gás (He et al., 1994).

Bacanamwo \& Purcell (1999a) demonstraram, em plantas dependentes da fixação de $\mathrm{N}_{2}$, que sete dias depois da inundação, no tratamento inundado, a fitomassa e o $\mathrm{N}$ total diminuíram 15 e $55 \%$, respectivamente, em relação às plantas-controle (não inundadas). Dos sete aos 14 dias após a inundação, contudo, a fitomassa e a taxa de acumulação de $\mathrm{N}$ foram aproximadamente metade da taxa dos controles, e de 14 a 21 dias, esses parâmetros igualaram-se ou excederam as taxas do controle. Portanto, a recuperação da fitomassa e da acumulação de $\mathrm{N}$ coincidiram com aumentos de porosidade de raízes, aerênquima e desenvolvimento de raízes adventícias, que se iniciaram aos sete dias após a inundação.

Cabe, no entanto, realizar maiores estudos em condições de inundação intermitente (que são mais próximas do que realmente ocorre no campo), para verificar se tais respostas em relação ao N são similares.

Os resultados demonstraram que a soja desenvolve mecanismos que permitem sua sobrevivência em ambiente de solo inundado, e supera restrições impostas pela hipoxia, por teores elevados de elemen-

Tabela 4. Parâmetros de crescimento de cultivares de soja em solo sob dois regimes hídricos ${ }^{(1)}$.

\begin{tabular}{|c|c|c|c|c|}
\hline \multirow[t]{3}{*}{ Regime hídrico } & \multicolumn{2}{|c|}{ Matéria seca } & \multirow{3}{*}{$\begin{array}{c}\text { Área foliar } \\
\left(\mathrm{cm}^{2} \text { planta }^{-1}\right)\end{array}$} & \multirow{3}{*}{$\begin{array}{c}\text { Estatura } \\
(\mathrm{cm})\end{array}$} \\
\hline & Parte aérea & Raízes & & \\
\hline & \multicolumn{2}{|c|}{ 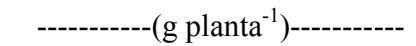 } & & \\
\hline Solo inundado & $1,57^{\mathrm{ns}}$ & $0,52 \mathrm{a}$ & $184^{\mathrm{ns}}$ & $43^{\text {ns }}$ \\
\hline Capacidade de campo & 1,43 & $0,39 \mathrm{~b}$ & 194 & 44 \\
\hline CV $(\%)$ & 16 & 20,3 & 12,7 & 14,2 \\
\hline
\end{tabular}

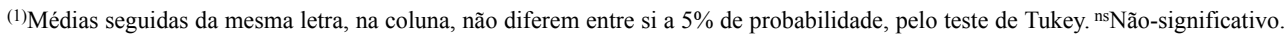




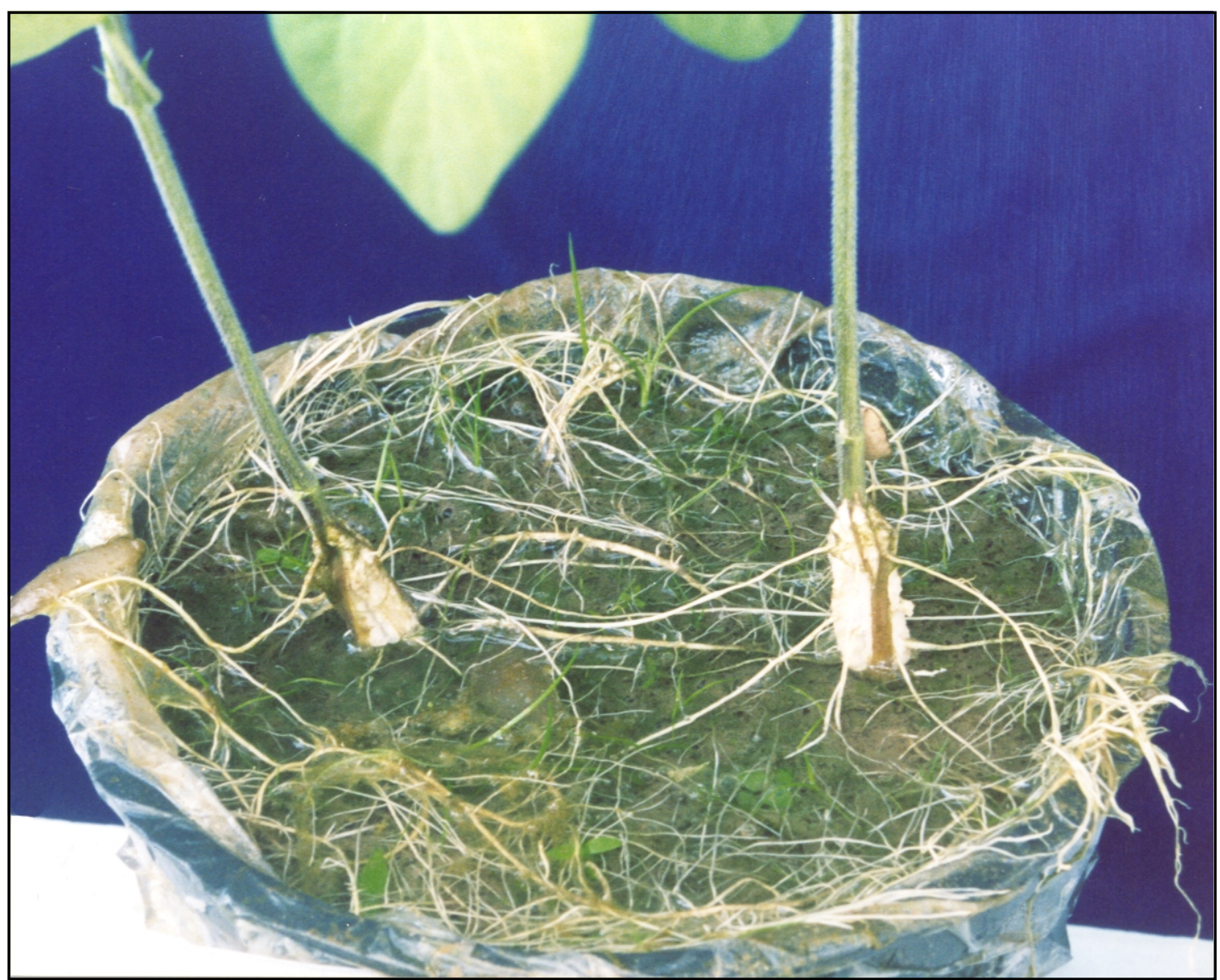

Figura 2. Fotografia mostrando hipertrofia da base do caule e raízes adventícias de plantas de soja (estádio V5) submetidas a inundação, por 21 dias, com lâmina de água de $3 \mathrm{~cm}$ acima da superfície do solo.

tos tóxicos, por desordens metabólicas e por redução na absorção de nutrientes. Esses mecanismos estão fundamentados basicamente na formação de aerênquima, que proporciona uma rota alternativa para fornecimento de oxigênio para as raízes, as quais têm por ponto de captação de oxigênio a região esponjosa que se forma no colo da planta (hipertrofia do caule). Possivelmente, o $\mathrm{N}_{2}$ utilizado pela fixação simbiótica utiliza o mesmo mecanismo, uma vez que a nodulação foi eficiente sob inundação. A tolerância à inundação pode estar associada à velocidade de formação do aerênquima, podendo haver diferença entre cultivares neste sentido.

Trabalhos anatômicos visando verificar diferenças no espaço aéreo do caule e da raiz, formado pela quebra de células, em diferentes cultivares, são necessários para verificar se há diferenças no fluxo de $\mathrm{O}_{2}$, o que pode caracterizar o maior ou menor grau de adaptação, uma vez que a principal diferença observada no presente trabalho foi o diâmetro do caule hipertrofiado na região submergida. Esse fluxo diferencial pode estar relacionado também a mecanismos de exclusão de $\mathrm{Fe}$, que provocam a formação de concreções de óxidos de Fe.

Outras espécies de leguminosas que ocorrem com freqüência em áreas alagadas podem servir como plantas-modelo para estudos de fixação simbiótica nesta situação. Em uma delas, Aeschynomene fluminensis, foram observadas conexões dos nódulos com o aerênquima do córtex, bem como o au- 
mento do tamanho dos nódulos com a inundação e a formação de nódulos no caule, com a presença de cloroplastos (Loureiro et al., 1995). Essas conexões podem estar ocorrendo também em soja.

A identificação de genótipos de soja tolerantes à inundação pode requerer a seleção de plantas que consigam manter o crescimento nessas condições, o que é proporcional às mudanças que ocorrem na morfologia das raízes. Alternativamente, o aumento da tolerância, pelo aumento na formação de aerênquima, pode requerer alterações genéticas para produzir um aerênquima constitutivo (Bacanamwo \& Purcell, 1999b).

A exploração de áreas alagadas com espécies de importância econômica depende da identificação não somente de plantas que sobrevivam à inundação do

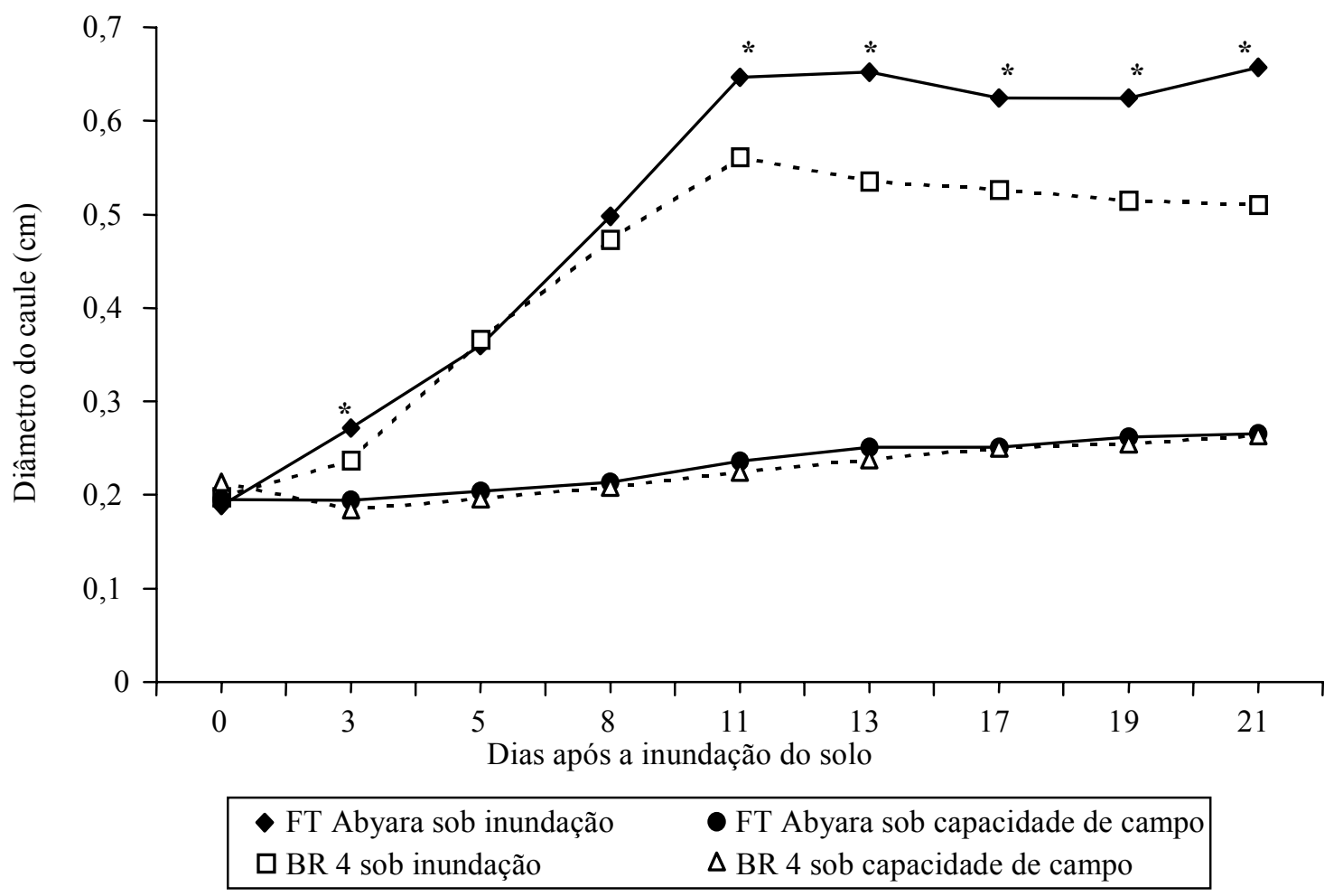

Figura 3. Diâmetro do caule a $2 \mathrm{~cm}$ da superfície do solo, de cultivares de soja em dois regimes hídricos, ao longo do tempo. Os asteriscos indicam que há diferença a $5 \%$ de probabilidade, pelo teste de Tukey, dentro de cada regime hídrico.

Tabela 5. Matéria seca (MS), área foliar (AF), matéria seca de nódulos (MSN), e teor de nitrogênio (N) nas folhas de duas cultivares de soja sob dois regimes hídricos (CC: capacidade de campo; I: solo inundado) e sob duas formas de fornecimento de $\mathrm{N}$ (uréia e inoculação) ${ }^{(1)}$.

\begin{tabular}{|c|c|c|c|c|c|c|c|c|}
\hline \multirow[t]{2}{*}{ Nitrogênio } & \multicolumn{2}{|c|}{ MS (g planta $\left.{ }^{-1}\right)$} & \multicolumn{2}{|c|}{$\mathrm{AF}\left(\mathrm{cm}^{2}\right.$ planta $\left.^{-1}\right)$} & \multicolumn{2}{|c|}{ MSN (g planta $\left.{ }^{-1}\right)$} & \multicolumn{2}{|c|}{$\mathrm{N}\left(\mathrm{g} \mathrm{kg}^{-1}\right)$} \\
\hline & $\mathrm{CC}$ & I & $\mathrm{CC}$ & I & $\mathrm{CC}$ & I & $\mathrm{CC}$ & I \\
\hline Uréia & $1,46 \mathrm{aB}$ & $1,78 \mathrm{aA}$ & $205 \mathrm{aA}$ & $201 \mathrm{aA}$ & $0,00 \mathrm{bA}$ & $0,00 \mathrm{bA}$ & $6,4 \mathrm{aA}$ & $5,3 \mathrm{aB}$ \\
\hline Inoculação & $1,39 \mathrm{aA}$ & $1,35 \mathrm{bA}$ & $182 \mathrm{aA}$ & $167 \mathrm{bA}$ & $0,06 \mathrm{aA}$ & $0,05 \mathrm{aA}$ & $3,2 \mathrm{bA}$ & $3,4 \mathrm{bA}$ \\
\hline
\end{tabular}

${ }^{(1)}$ Médias seguidas da mesma letra, maiúscula na linha e minúscula na coluna, não diferem entre si, a $5 \%$ de probabilidade, pelo teste de Tukey; os coeficientes de variação em relação a matéria seca, área foliar, matéria seca de nódulos e teor de nitrogênio foram 16,0\%, 12,7\%, 19,5\% e 4,6\%, respectivamente. 
solo, mas que também apresentem rendimentos capazes de trazer retorno econômico. Tal tarefa deve associar trabalhos de curta duração em casa de vegetação, mas também experimentos de campo visando simular condições e períodos diferenciados de inundação. Para tanto, devem ser identificados genótipos mais tolerantes, e depois, buscar as razões que levam a esta melhor adaptação, no aspecto anatômico, morfológico, metabólico e fisiológico, possibilitando a transferência de tais características para cultivares que não as possuem, por meio de técnicas de melhoramento.

\section{Conclusões}

1. A soja apresenta mecanismos que permitem sua adaptação a condições de hipoxia gerados pela inundação do solo.

2. Há redução nos teores de $\mathrm{N}, \mathrm{K}, \mathrm{Mg}$ e $\mathrm{Mn}$, e aumento nos teores de Fe nas folhas, como efeito da inundação.

3. Existe diferença entre cultivares em solo inundado.

4. O diâmetro do caule sob a lâmina de água é a característica mais importante na diferenciação de cultivares com relação à tolerância à inundação.

5. Na fase inicial de desenvolvimento, a soja responde mais à aplicação de $\mathrm{N}$ em cobertura do que à inoculação das sementes.

6. Mesmo sob inundação, ocorre nodulação em soja.

\section{Referências}

BACANAMWO, M.; PURCELL, L. C. Soybean dry matter and $\mathrm{N}$ accumulation responses to flooding stress, $\mathrm{N}$ sources, and hypoxia. Journal of Experimental Botany, Oxford, v. 50, n. 334, p. 789-796, 1999a.

BACANAMWO, M.; PURCELL, L. C. Soybean root morphological and anatomical traits associated with acclimation to flooding. Crop Science, Madison, v. 39, n. 1 , p. $143-149,1999$ b.

BARNI, N. A. Efeito do período de inundação do solo na absorção de nutrientes, uso da água e crescimento da planta de soja. Pesquisa Agropecuária Gaúcha, Porto Alegre, v. 5 , n. 1 , p. 7-18, 1999.
BARNI, N. A.; LOPES, M. S.; HILGERT, E. R.; SARTORI, G.; GONÇALVES, J. C.; GOMES, J. E. da S. Avaliação agronômica de cultivares de soja (Glycine max (L.) Merrill) em solos hidromórficos. Agronomia Sulriograndense, Porto Alegre, v. 21, n. 2, p. 189-207, 1985.

BARTLETT, R. J.; JAMES, B. R. Redox chemistry of soil. Advances in Agronomy, San Diego, v. 50, p. 151-208, 1993.

COSTA, J. A. Cultura da soja. Porto Alegre: Evangraf, 1996. $233 \mathrm{p}$.

COSTA, J. A.; MARCHEZAN, E. Características dos estádios de desenvolvimento da soja. Campinas: Fundação Cargill, 1982. 30 p.

DEDATTA, S. K. Principles and practices of rice production. New York: J. Wiley, 1981. 618 p.

DE-POLLI, E.; FRANCO, A. A.; DÖBEREINER, J. Sobrevivência de Rhizobium em solos de baixada sujeitos a inundação. Pesquisa Agropecuária Brasileira, Brasília, v. 8, n. 7, p. 133-138, 1973.

DREW, M. C.; HE, C.; MORGAN, P. W. Programmed cell death and aerenchyma formation in roots. Trends in Plant Science, Oxford, v. 5, n. 3, p. 123-127, 2000.

DREW, M. C.; STOLZY, L. W. Growth under oxygen stress. In: WAISEL, Y.; ESHEL, A.; KAFKAFI, U. (Ed.). Plant roots: the hidden half. New York: M. Dekker, 1991. p. 331-350.

ELKHATIB, E. E.; HERN, J. L.; STALEY, T. E. A rapid centrifugation method for obtaining soil solution. Soil Science Society of America Journal, Madison, v. 51, n. 3, p. 578-583, 1987.

FERNANDES, F. E. Fatores relacionados à acidez de solos e sua influência no desenvolvimento e absorção de cálcio, magnésio, manganês e alumínio por feijão e milho. Porto Alegre: UFRGS, 1989. 131 p. Dissertação de Mestrado.

GASTAL, M. F. da C.; BRANCÃO, N.; VERNETTI, F. de J. Indicação de cultivares de soja para terras baixas. Agropecuária de Clima Temperado, Pelotas, v. 1, n. 1, p. 95-99, 1998.

HE, C.; DREW, M. C.; MORGAN, P. W. Induction of enzymes associated with lysogenous aerenchyma formation in roots of Zea mays during hypoxia or nitrogen starvation. Plant Physiology, Rockville, v. 105, p. 861-865, 1994.

HE, C.; MORGAN, P. W.; DREW, M. C. Transduction of an ethylene signal is required for cell death and lysis in 
the root cortex of maize during aerenchyma formation induced by hypoxia. Plant Physiology, Rockville, v. 112, p. 463-472, 1996.

JACKSON, M. B. Ethylene and responses of plants to soil waterlogging and submergence. Annual Review of Plant Physiology and Plant Molecular Biology, Palo Alto, v. 36, p. $145-174,1985$.

LOUREIRO, M. F.; JAMES, E. K.; SPRENT, J. I.; FRANCO, A. A. Stem and root nodules on the tropical wetland legume Aeschynomene fluminensis. New Phytologist, Cambridge, Inglaterra, v. 130, p. 531-544, 1995.

MARSCHNER, H. Mineral nutrition of higher plants. San Diego: Academic, 1995. 889 p.

REUNIÃO DE PESQUISA DE SOJA DA REGIÃO SUL, 26., 1998, Cruz Alta. Recomendações técnicas para a cul- tura da soja no Rio Grande do Sul e em Santa Catarina: 1998/99. Cruz Alta: Unicruz, 1998. 133 p.

SFREDO, G. J.; CARRÃO-PANIZZI, M. C. C. Importância da adubação e da nutrição na qualidade da soja. Londrina: Embrapa-CNPSo, 1990. 57 p. (Documentos, 40).

SMIT, B. A.; NEUMANN, D. S.; STACHOWIAK, M. L. Root hypoxia reduces leaf growth: role of factors in the transpiration stream. Plant Physiology, Rockville, v. 92, p. 1021-1028, 1990.

TEDESCO, J. M.; GIANELLO, C.; BISSANI, C. A.; BOHNEN, H.; WOLKWEISS, S. J. Análise de solo, planta e outros materiais. 2. ed. amp. Porto Alegre: UFRGS, 1995. 174 p. (Boletim Técnico, 5).

VANTOAI, T. T.; BEUERLEIN, J. E. Genetic variability for flooding tolerance in soybeans. Crop Science, Madison, v. 34, p. 1112-1115, 1994. 